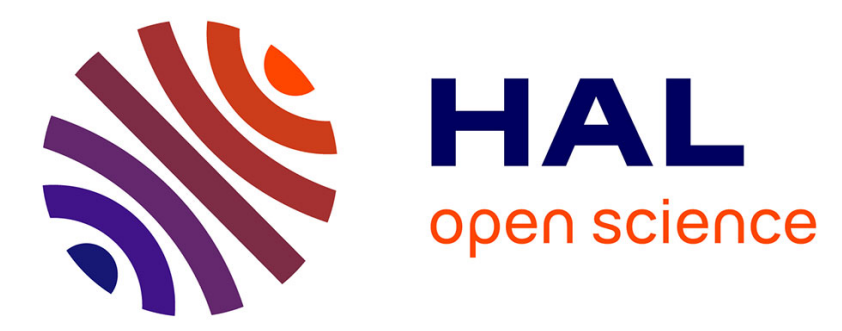

\title{
Experimental study of the mechanical behaviour of thin slices of maturating green poplar wood using cyclic tensile tests
}

Guillaume Pot, Catherine Coutand, Jean-Benoit Le Cam, Evelyne Toussaint

\section{To cite this version:}

Guillaume Pot, Catherine Coutand, Jean-Benoit Le Cam, Evelyne Toussaint. Experimental study of the mechanical behaviour of thin slices of maturating green poplar wood using cyclic tensile tests. Wood Science and Technology, 2013, 47 (1), pp.7-25. 10.1007/s00226-012-0477-8 . hal-00830323

\section{HAL Id: hal-00830323 \\ https://hal.science/hal-00830323}

Submitted on 2 Jun 2020

HAL is a multi-disciplinary open access archive for the deposit and dissemination of scientific research documents, whether they are published or not. The documents may come from teaching and research institutions in France or abroad, or from public or private research centers.
L'archive ouverte pluridisciplinaire HAL, est destinée au dépôt et à la diffusion de documents scientifiques de niveau recherche, publiés ou non, émanant des établissements d'enseignement et de recherche français ou étrangers, des laboratoires publics ou privés. 


\title{
Experimental study of the mechanical behaviour of thin slices of maturating green poplar wood using cyclic tensile tests
}

\author{
Guillaume Pot • Catherine Coutand • \\ Jean-Benoît Le Cam $\cdot$ Evelyne Toussaint
}

\begin{abstract}
In this study, longitudinal cyclic tensile tests were performed on green wood samples of Populus cv I4551. Complex mechanical behaviour, such as permanent set in terms of displacement and strain-dependent stiffness, was found. A linear relationship between stiffness and strain enabled each sample to be characterized. A large-scale experimental campaign led to the observation of the evolution of temporal and spatial intra-ring mechanical behaviour of intra-ring sliced specimens during wood maturation and tree gravitropic response. The results showed that tension wood lamellas exhibit strain hardening behaviour whereas normal wood lamellas exhibit strain softening behaviour. Temporal variations in the strain hardening behaviour of tension wood lamellas occurred once cell wall
\end{abstract}

G. Pot $\cdot$ E. Toussaint $(\bowtie)$

Université Blaise Pascal, Institut Pascal, Clermont Université, BP 10448,

63000 Clermont-Ferrand, France

e-mail: evelyne.toussaint@ifma.fr

G. Pot $\cdot$ E. Toussaint

UMR 6602, Institut Pascal, CNRS, 63171 Aubière, France

e-mail: guillaume.pot@ifma.fr

C. Coutand

UMR 547 PIAF, INRA, 63100 Clermont-Ferrand, France

e-mail: catherine.coutand@clermont.inra.fr

C. Coutand

Université Blaise Pascal, UMR 547 PIAF, Clermont Université,

63000 Clermont-Ferrand, France

J.-B. Le Cam

L.A.R.M.A.U.R. - CNRS 6274, Université de Rennes 1, Campus de Beaulieu, 35042 Rennes, France

e-mail: jean-benoit.lecam@univ-rennes1.fr 
deposition was achieved. Moreover, no correlation was found between infradensity and mechanical behaviour of lamellas. These results show that cells undergo temporal variations in their properties due to a complex maturation process.

\section{Introduction}

Tree axes grow in length in their apical parts (primary growth), whereas pre-existing parts grow in diameter thanks to secondary cambium, by which wood cells are produced at the periphery of the trunk. Wood fibres are created and matured by a complex developmental process that consists of five major steps: (1) cell division from the vascular cambium, (2) elongation and radial enlargement, (3) secondary cell wall deposition and lignification, (4) programmed cell death and (5) heartwood formation (Déjardin et al. 2010; Plomion et al. 2001). Trees control their posture by maintaining and modifying the orientation of their trunk and branches in space. Asymmetrical production of reaction wood ensures these gravitropic movements in plant parts that have achieved their elongation (Scurfield 1973). In most deciduous species, reaction wood is called tension wood (TW) because it is under high tension within the living tree (Sinnott 1952). Wood is thus pre-stressed, and TW pre-stresses are more important than in opposite wood (OW). Considering a tilted axis (e.g. trunk) of a deciduous species, TW is first produced on the upper side (true gravitropic phase) and then on the opposite side (autotropism phase) in order to be, finally, straight and vertical (Coutand et al. 2007). Formation, growth and anatomical characteristics of TW in poplar trees in relation to the gravitational stimulus are detailed in literature (Jourez et al. 2001, 2003; Jourez and Avella-Shaw 2003). In most angiosperm species, TW typically includes a so-called gelatinous layer ( $\mathrm{G}$ layer), which is essentially made up of highly crystalline cellulose, with a very low microfibril angle (MFA). However, its function in TW shrinkage is still controversial (Goswami et al. 2008; Clair et al. 2010). Very little data are available in the literature concerning the properties of TW, and to the authors ' knowledge, there has been no study of TW response to longitudinal tensile tests in wet conditions.

Biomechanical models designed to simulate gravitropic movements and to predict reaction wood zones exist (Fournier et al. 1994, 2006; Yamamoto et al. 2002; Alméras and Fournier 2009; Coutand et al. 2011). Most of these models consider secondary growth as an incremental problem and wood as a linear elastic material. In the biomechanical model proposed by Alméras and Fournier (2009), the longitudinal wood modulus can change according to the circumferential position (because of the difference between TW and OW), but without any temporal or radial intra-ring variations. The maturation process is assumed to be instantaneous, that is, cell maturation occurs instantaneously once the cell has left the cambium. Therefore, maturation strains are immediately locked in, and mechanical properties change instantaneously. Coutand et al. (2007) noted that in the case of temporal integration with a time step of 1 week, such biomechanical models no longer fit the experimental data. They formulated two hypotheses to explain this discrepancy: (1) spatial and/or temporal changes in the TW pre-stress levels during the gravitropic 
response are significant and become more important than geometrical effects, and (2) time lag between radial growth and the differentiation of a cell into TW fibres cannot be neglected at short time scales. To investigate these hypotheses, information about the temporal and spatial evolution of TW mechanical properties during secondary growth is required.

To the authors " knowledge, there is no study that deals with either intra-ring spatial or temporal changes during maturation. Nevertheless, many publications provide data concerning earlywood/latewood anatomical or mechanical differences. Some of them present results from longitudinal tensile tests performed at intra-ring scale with wet or dry wood samples. Moliński and Krauss (2008) focused on latewood and earlywood and determined a radial gradient of longitudinal modulus of elasticity (MOE) in a 62-year-old pine. To do this, they performed tensile tests on air-dried samples cut in longitudinal direction using a microtome. The sample dimensions were $0.2 \mathrm{~mm}(R) \times 10 \mathrm{~mm}(T) \times 120 \mathrm{~mm}(L)(R, T$ and $L$ indicate the radial, tangential and longitudinal directions, respectively). They also evaluated density variations within the annual rings by measuring the volume and weight of their samples and measured their MFA. They found a non-linear relation between MOE and wood density, but concluded that the main reason for the observed significant change in the MOE was the change in MFA. Bjurhager et al. (2008) used samples cut with a microtome for which dimensions were close to those of Molinski, but they worked on wet juvenile European aspen and hybrid aspen. They evaluated MOE evolution on juvenile wood with respect to the distance from the pith and found a slight MOE increase as this distance became greater.

Both of these studies performed monotonic tensile tests to determine MOE. However, Navi et al. (1995) showed that such specimens with a small number of fibres present complex tensile stress-strain behaviour, distinctly different from that obtained in bulk wood. Navi's samples were cut in longitudinal direction using a plane in order to obtain a cross-section of $0.15 \mathrm{~mm}(R) \times 2 \mathrm{~mm}(T)$. These samples subjected to loading-unloading cycles with increasing maximum loading at each cycle exhibited a permanent set in terms of displacement. During the loading of each cycle, the force-displacement curve was nearly a straight line until it reached the previous maximum displacement. Such behaviour was recently confirmed for single compression wood fibre (Gilani and Navi 2007). Moreover, the authors showed that, under such loading conditions, wood stiffness increases during loading. It should be noted that a similar mechanical response has already been reported for natural fibres like flax (Baley 2002). The authors explained that such phenomena were due to microfibril angle (MFA) reduction and matrix damaging. These observations highlight the fact that the behaviour of such materials strongly depends on the load history. Such considerations are not taken into account in biomechanical models, and MOE is usually calculated from the initial part of the stress-strain curve.

Considering the lack of data concerning changes in the mechanical properties of wood during maturation, the aim of the present study is to characterize, spatially and temporally, variations in the intra-ring mechanical behaviour of TW during the radial growth of the tree and its gravitropic response. For this purpose, the authors attempted to define a mechanical quantity that characterizes green TW thin slices 
and their maturation. As the TW pre-stress level is regulated by mechanosensing, experimental work was performed on a set of trees whose mechanical states differed: tilted trees that were free to right up (their curvature and the tilting angle of the trunk varies all along the gravitropic response) and tilted trees that were staked in a fixed position (whose curvature remains null and their trunks keep tilted with a constant angle from the vertical). Although this work focuses on TW, the OW of these trees was also studied using the same experimental protocol.

\section{Materials and methods}

Variations in the mechanical behaviour of TW in the radial direction at intra-ring scale were characterized by means of longitudinal mechanical tests performed on numerous thin intra-ring samples. These samples represent together the growth ring of a given tilted tree. Similarly, the temporal evolution of the mechanical behaviour of TW was characterized using the same tests. For this purpose, tilted trees were felled weekly at different times during the growing season (i.e. at different stages of the gravitropic process).

Field experimental design

The work was carried out on eighteen 1-year-old hybrid poplars (Populus deltoids $\times$ Populus nigra) "I4551" planted in individual 60-L containers filled with Limagne soil in January 2010 . The trees were tilted by tilting the pot about $35^{\circ}$ from the vertical on 3 June 2010 at the start of the second year's growth, following the procedure described in Coutand et al. (2007). Since the trunks were not perfectly straight and because of the weight effect, tilting was adjusted for each trunk so that the mean angle between the first quarter of the trunk and the vertical axis was $35^{\circ}$. All the containers were then buried in soil to limit their movements and to maintain normal temperature around the roots. The trees were watered continuously by individual watering devices throughout the experiment. As the trees were not subjected to high mechanical disturbances before burying, they should be composed of so-called "Normal Wood" (NW) with an insignificant amount of TW at the beginning of the experiment.

There were two series of experiments: nine trees were free to right up, while the nine others were staked in a tilted position in order to keep their trunk straight with a constant tilting angle from the vertical during growth until they were felled. Comparing staked-tilted trees with free trees allowed observing gravitropic movement effects on the evolution of the wood mechanical properties. In most cases, free trees reached a vertical position in less than 2 months. Staked-tilted trees pulled on their stake, but remained tilted until they were released at the end of the experiment.

Each week from 15 June to 10 August, one tree of each series was felled. Each trunk was then cut into sections approximately $30 \mathrm{~cm}$ long, taken from the trunk base up to $1 \mathrm{~m}$ in height. These samples were stored in water in plastic containers at $4{ }^{\circ} \mathrm{C}$ in a refrigerator. 


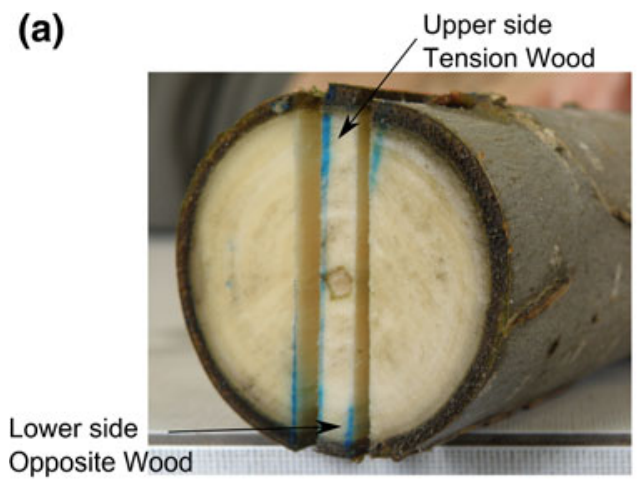

(c)

Opposite Wood

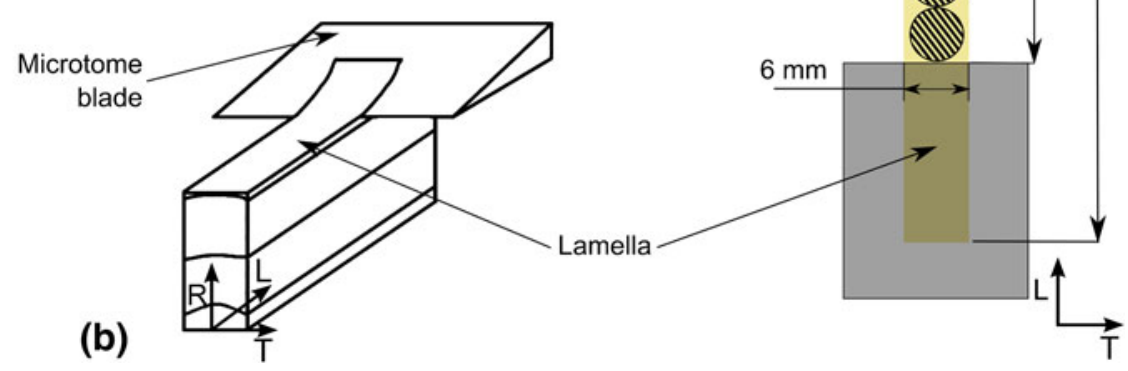

Fig. 1 a Image of the cross-section of a log from which a plank has been cut along the diameter running from the upper side to the lower side of the tilted tree; $\mathbf{b}$ diagram of the half plank from which lamellas were cut with a microtome; $\mathbf{c}$ diagram of a lamella placed into machine grips and position of micrometer measurements (hatched circles)

\section{Wood sample preparation}

Samples of $7 \mathrm{~cm}$ in length were taken from the $30-\mathrm{cm}$ sections previously cut from each trunk. In order to ensure the homogeneity of the material, trunk knots were avoided when selecting the sampling zone. Thus, the height from the ground at which the samples were taken was not exactly the same for each tree, varying from 3 to $18 \mathrm{~cm}$. From these $7-\mathrm{cm}$-long segments, a piece of $6 \mathrm{~mm}$ in width was cut with a band saw in such a way that the saw cuts were parallel to the diameter running from the upper side to the lower side of the tilted tree (see Fig. 1a). By sawing along the pith, the lower side, containing OW, was separated from the upper side, containing TW induced by artificial tilting. Next, the same experimental treatment was performed on the two sides: first, the bark was manually removed so that the cambium became visible; then, 200- $\mu \mathrm{m}$-thick samples were gradually cut, using a sliding microtome, from the cambium to the innermost growth ring (Fig. 1b). As opposed to saw cutting, the use of a sliding microtome ensures that material is not lost between each lamella. Each lamella was stored in water in a test tube. These lamella samples were in the longitudinal-tangential plane $(70 \times 6 \mathrm{~mm})$ with $200 \mu \mathrm{m}$ thickness in the radial direction. As a consequence, the whole sequence of these lamellas represented the intra-ring radial variation of the wood. 
Prior to the tensile test, the width of each lamella was measured using a slide calliper; its thickness was measured at five locations along the 30-mm-long tested region using a Mitutoyo micrometer with $0.001 \mathrm{~mm}$ resolution (Fig. 1c). The mean thickness was $204 \pm 16 \mu \mathrm{m}$. These measurements enabled the volume of the tested region of the wet sample to be calculated. After the tensile test, the 30-mm-long tested region was cut out from the 70 -mm-long sample. It was dried at $105{ }^{\circ} \mathrm{C}$ for $24 \mathrm{~h}$ and then weighed. Dry weight over wet volume gave the infradensity of each lamella.

Since the samples were numbered from the cambium to the innermost growth ring, the measurements were used to calculate the distance from the first lamella to the considered lamella by adding the mean thickness of the previous ones. Thus, it became possible to represent wood parameters obtained from each lamella such as infradensity as a function of its radial distance measured from the first lamella. Here, radial distance was measured as the distance from the first lamella which could be cut, and not from the cambium, because the very first cells in the cambial zone were close to the liquid state and did not enable a lamella to be cut out with homogenous dimensions.

Cyclic tensile tests

\section{Test conditions}

Lamellas were tested in their longitudinal direction using an Instron 5543 tensile testing machine with a $50 \mathrm{~N}$ load cell. The tested region was $30 \mathrm{~mm}$ in length in order to have a significant part of the sample in the grip (Fig. 1c) and to have a fully homogenous area (thickness close to the extremities of the lamellas could vary because of the microtome cutting). As the serrated jaw faces of the machine were too aggressive for the samples, small metal plates covered with sandpaper were used to maintain the lamellas without any sliding or damage.

Tests were performed under controlled displacement conditions with a constant tensile rate of $1 \mathrm{~mm} / \mathrm{min}$, which is consistent with literature (e.g. Goswami et al. 2008; Bjurhager et al. 2008). The deformation rate was about $4 \times 10^{-4} \mathrm{~s}^{-1}$. Longitudinal force and cross-head displacement were recorded every $0.3 \mathrm{~s}$. The tensile test was sequenced in six increasing load cycles. Indeed, although the sample was stretched at a constant displacement rate during a cycle, elongation was stopped at a given load and displacement then decreased at the same rate until $0 \mathrm{~N}$. Then, the next cycle was performed. For each cycle, the maximum load was increased in steps of $6 \mathrm{~N}$ from 6 to $36 \mathrm{~N}$. Most of the samples usually ruptured before $36 \mathrm{~N}$, especially those which were close to the cambium.

Digital image correlation (DIC) using CORRELI ${ }^{\text {LMT }}$ software (Hild 2002) was used to measure full-field displacements without contact. This enabled to record the displacement field at the sample surface; therefore, it was possible to check the homogeneity of the displacement field. The DIC method consists of matching, before and after displacement, a set of zones of interest (ZOI), which make up a 
region of interest (ROI) on the observed surface of the specimen. For this study, the ROI was the entire area tested, that is, $30 \mathrm{~mm}(L) \times 6 \mathrm{~mm}(W)$, which represented an image size of about $1,000 \times 200$ pixels, while the ZOI were $32 \times 32$ pixels. To adjust image brightness and improve contrast, a spotlight was used, and black paint was sprayed onto the sample surface prior to testing.

Images were taken with a cooled 12-bit dynamic CCD camera at a rate of 5 images per second. The first image was referred to as the reference image, since the sample did not experience any loading. The following images were correlated with the reference image using the DIC method. Displacements in longitudinal direction were then computed using CORRELI ${ }^{\mathrm{LMT}}$ software.

\section{Data analysis}

Most of the samples exhibited homogenous linear displacements. Thus, for each correlated image, a planar interpolation was performed, and longitudinal deformations were obtained by computing the slope of each corresponding plane. Samples showing non-linear displacements were removed from the data set. Such samples were usually found in zones where there was a material discontinuity, like in the growth ring limit region, for instance.

Figure 2 presents a typical stress/strain curve of poplar TW lamella plotted using these data and the previously measured cross-section of the sample. Force historydependent behaviour was noted: the stiffness depended on the loading level. The linear shape of the loading phase of each cycle was also noticed. Thus, for each cycle of each sample wood, stiffness was calculated by linear interpolation over the reloading phase (dashed line in Fig. 2). The reloading phase was defined as the region between zero load and the maximum strain value obtained from the previous cycle. Therefore, for each sample, stiffness depends on the cycle being considered.

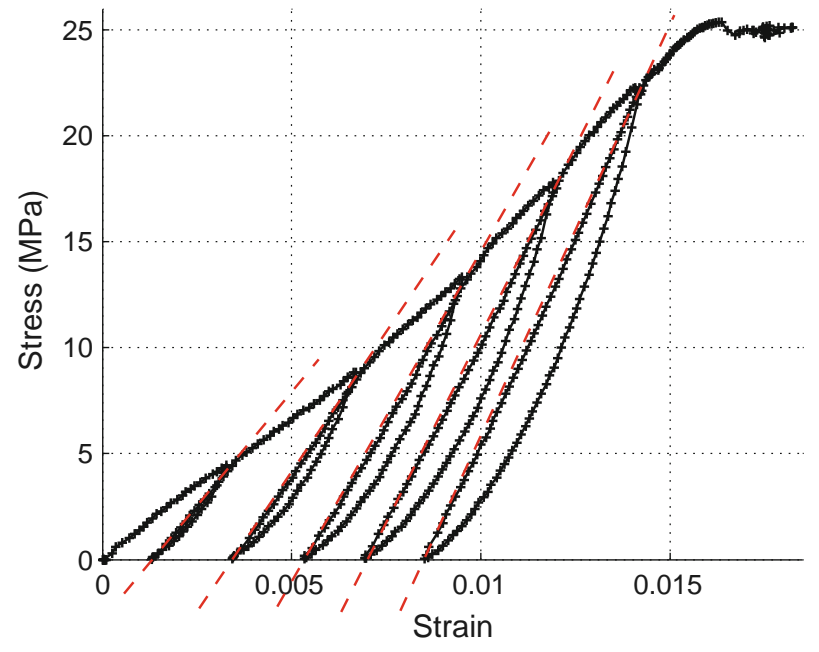

Fig. 2 Typical cyclic tensile test curve of a tension wood sample. The dashed lines fit the quasi-linear reloading phase for each cycle 


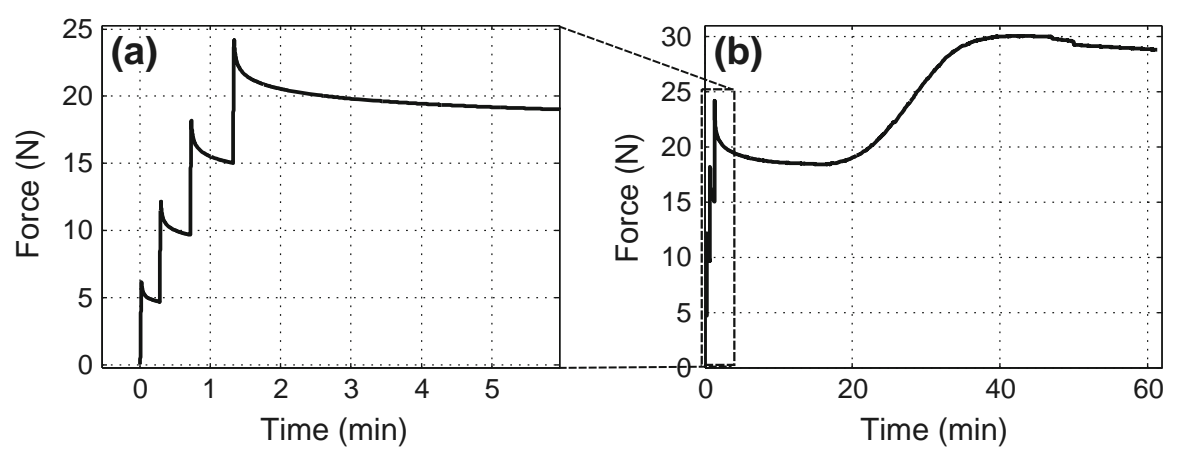

Fig. 3 "Relaxation-drying" test of a tension wood sample. a Zoom of the beginning of the test, (b) whole 1-h test

This stiffness is called "Cycle Stiffness in the Reloading Phase" (CSRP). Figure 2 shows that CSRP depended on the cycle: the higher the maximum previous strain, the higher the corresponding stiffness. Thus, the higher the applied deformation was, the stiffer the TW. As a consequence, green wood stiffness could not be studied regardless of applied strain (or stress). This conclusion led to the specific experimental protocol defined previously, for which cycles with increasing loads scan the range of possible strains.

Preliminary drying tests prior to tensile tests

Testing green wood required that no drying should occur during the tensile test, since such drying would significantly affect the mechanical properties of the wood.

First, the weight of the samples left on the bench at $24{ }^{\circ} \mathrm{C}$ was continuously recorded. Water evaporated from the wood, and thus, sample weights decreased until equilibrium with the air moisture content was reached. Equilibrium was reached within 30 min (data not shown). However, it was not possible to conclude from this result that there was no change in mechanical properties before this time: bound water might have evaporated before equilibrium was reached.

Therefore, a second test was performed, which consisted of a "relaxationdrying" test, where the force was recorded over time, while sample displacement was maintained constant. In order to compare this test with the tensile test of the authors, the relaxation load increased in the same manner as for tensile testing, that is, the maximum load was increased in steps of 6 N. Samples were clamped in the same way as in the authors' tensile test. The load was applied quickly at a crosshead rate of $5 \mathrm{~mm} / \mathrm{min}$, and displacement was then maintained during a given time, corresponding to a typical cycle time for the tensile test (see example in Fig. 3a). For the last relaxation load, displacement was maintained for $1 \mathrm{~h}$.

Figure 3 shows typical relaxation-drying curves obtained for a TW sample. During each incremental loading (Fig. 3a), the force decreased during the relaxation time since green wood is a viscoelastic material. During the last hour for which the displacement was maintained, the force first decreased because of wood relaxation, 
but between about 20 and $40 \mathrm{~min}$, the force increased. This effect was due to drying, since fibres shrink when bound water evaporates. Thus, it was assumed that there was no drying effect that could disturb the tensile test results, since the tests lasted 5 min at most.

\section{Results}

In this section, the spatial variation in infradensity is first presented as a function of the radial distance from the first lamella. Then, the results obtained with cyclic tensile tests are given for each tree tested. Finally, the results are processed to determine the temporal evolution of the behaviour of TW.

Infradensity spatial variation

Figure 4a shows a typical infradensity curve obtained for TW samples with respect to the radial distance from the first lamella. A TW cross-section was examined under controlled moisture conditions (Fig. 4b, c) with an ESEM (Environmental

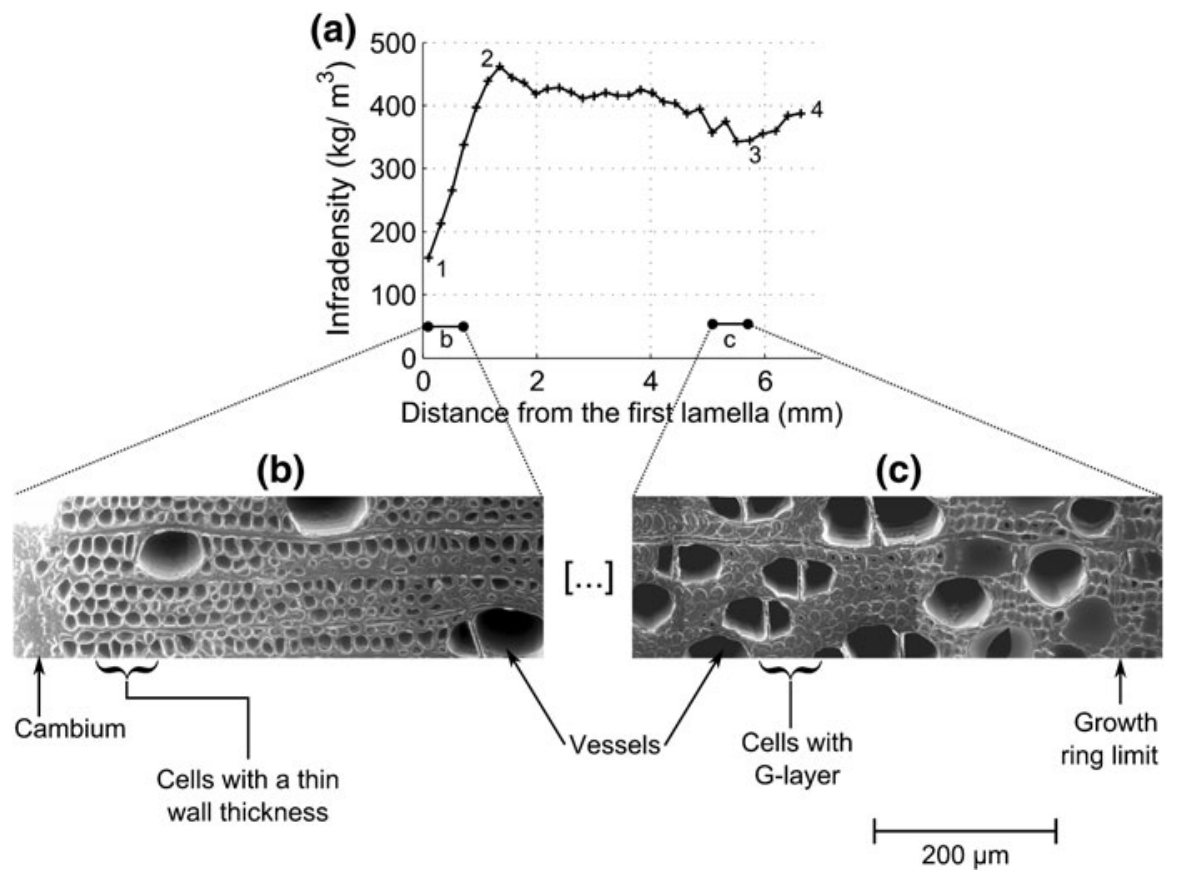

Fig. 4 a Typical infradensity curve depending on the radial distance from the first lamella. Region 1-2 corresponds to the increase in cell wall thickness; region 2-3 highlights an intra-ring decrease in infradensity; region 3-4 is the beginning of the previous annual ring. b ESEM observation of the near cambial zone. The cambium has been damaged by the experimental treatment, but wall thickness enlargement is well distinguishable. c ESEM observation of the growth ring limit zone which is highly vascularized. Tangentially elongated cells mark the boundary of the growth rings 
Scanning Electron Microscope) from the Max Planck Institute of Colloids and Interfaces. Qualitatively, the infradensity increase (1-2 region in Fig. 4a) in the first millimetre after the cambium seemed to follow the increase in cell wall thickness (observable in Fig. 4b). Hence, at point 2, cell wall thickening was assumed to be complete. In the 2-3 region presented in Fig. $4 \mathrm{a}$, the infradensity curve slightly decreased along the radius until reaching a minimum (point 3). Qualitative local ESEM observations did not enable clear explanation of this slight decrease. However, anatomical observations explained the origin of the minimum by the presence of a large number of vessels, that is, large empty areas with low infradensity (Fig. 4c). This is consistent with the fact that deciduous species have numerous vessels at the beginning of the growing season (although there is no clear earlywood/latewood transition for poplar). Finally, the last region of the infradensity curve between points 3 and 4 showed an increase in infradensity in proportion to the distance from the first lamella. This last region corresponded to the beginning of the growth ring of the previous year. The two sets of experiments (tilted trees that were free to right up and tilted trees that were staked) gave similar results in terms of infradensity.

Using the infradensity minima (i.e. the growth ring limits) of each tree as the origin of the abscissa and inverting the axis, infradensity curves were plotted for each tree according to the distance from the defined growth ring limit. Such curves are presented in Fig. 5a, b for TW for free and staked-tilted trees, respectively. This presentation is very useful to see the variation in infradensity according to the radial position in the tree and thus to compare trees. It can be noticed that: (1) the infradensity reached once cell wall thickening was complete was of the same order of magnitude for all the trees; (2) from a spatial point of view, the region corresponding to the infradensity increase on the TW side was about $1 \mathrm{~mm}$ long; (3) considering each tree independently, infradensity was higher at the end of the growing season than at the beginning.

Opposite wood results are not shown but, as for TW, growth ring limits were easily defined thanks to the region where infradensity decreased. As already observed on the same poplar clone (Coutand et al. 2007), the trees presented less OW than TW because of the asymmetrical growth of the stem induced by the tilting treatment.

Mean infradensity was calculated on the plateau zone (2-3 region in Fig. 4a) for OW and TW. OW mean infradensity was $347 \pm 28 \mathrm{~kg} \mathrm{~m}^{-3}$, and it was $405 \pm 32 \mathrm{~kg} \mathrm{~m}^{-3}$ for TW. A student $\mathrm{t}$ test was performed in order to compare these means of infradensity. The results show that the means were significantly different at a confidence level higher than $99 \%$.

\section{Cyclic tensile tests}

Cyclic tensile tests were performed on all the lamellas from the cambium to the growth ring limit, which generated numerous stress/strain curves. Figure $6 a-c$ shows the stress/strain curves of lamellas cut out from the upper side of the free tree felled on 20 July 2010. These lamellas were located in the last growth ring (i.e. they 


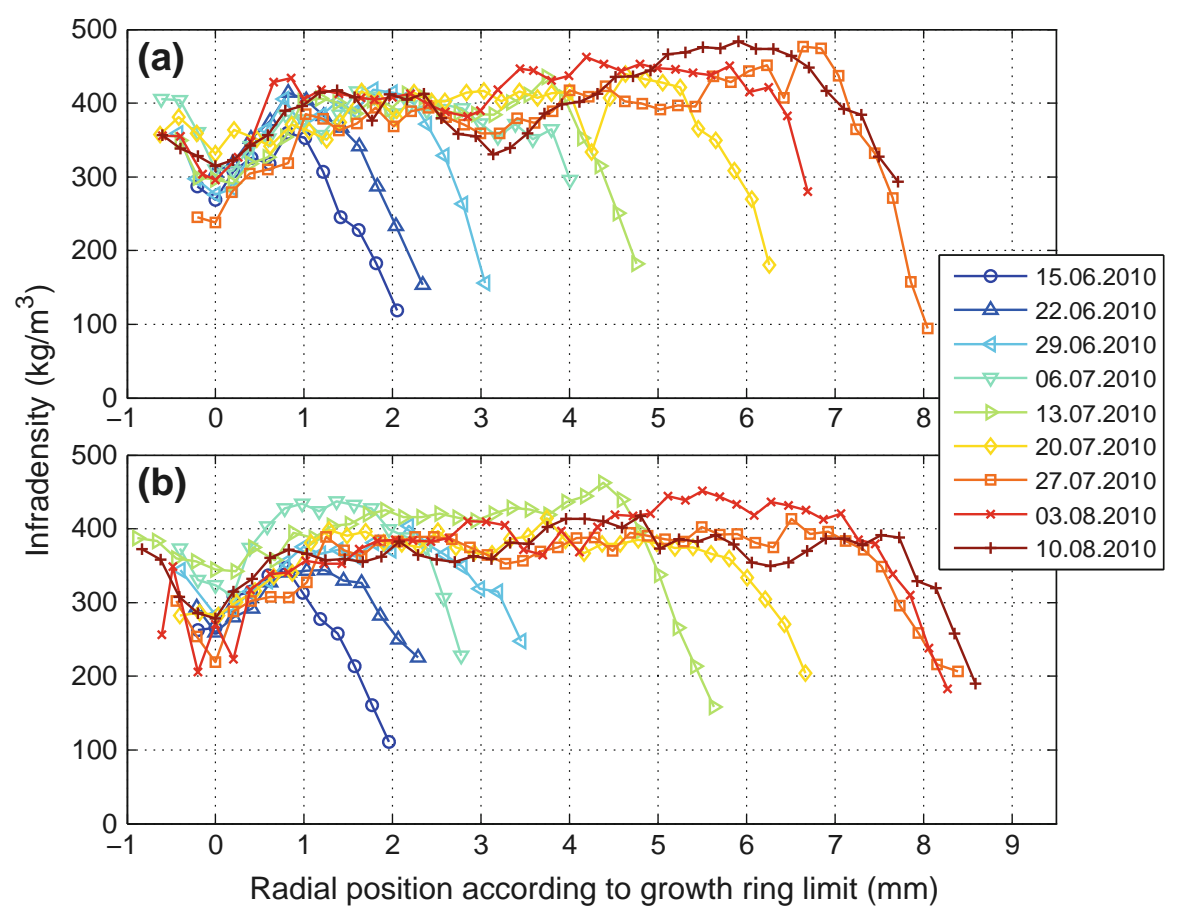

Fig. 5 TW infradensity variation according to the distance from the defined growth ring limit for a trees that were free to right up and $\mathbf{b}$ staked-tilted trees, felled at different dates throughout the growing season

were composed of TW), whereas the 31st lamella (Fig. 6d) was located in the previous annual ring (i.e. it was composed of NW).

The first lamellas close to the cambium were too weak to attain the load of $6 \mathrm{~N}$ necessary to perform a cycle as defined in the experimental protocol. In the case of this particular tree, the first lamella that reached a $6 \mathrm{~N}$ load was the third one (Fig. 6a). Thus, a first cycle was performed. However, this 3rd lamella was damaged before reaching $12 \mathrm{~N}$, so it could not undergo a second cycle. Although the first lamellas were too weak to reach the highest loads defined by the experimental protocol, the subsequent ones were strong enough to perform several cycles (see for instance the 8th lamella in Fig. 6b). It can be noticed that the number of cycles is not the same for all the samples (even for samples which were far from the cambium) because their strength seems to vary along the radius of the tree.

For TW lamellas, strain/stress curves consistently presented strain hardening behaviour, which can be observed in Fig. 6b, c, as well as in Fig. 2. Moreover, the shape of the stress/strain curves can be significantly different from one lamella to another. Indeed in this example, a lamella located at a distance of $2.8 \mathrm{~mm}$ from the cambium (Fig. 6c) presented a CSRP which, according to the cycle, increased faster than for a sample located at a distance of $1.4 \mathrm{~mm}$ from the cambium (Fig. 6b). Furthermore, contrary to TW samples, NW samples located in the previous annual ring exhibited strain softening behaviour and a brittle failure (Fig. 6d). 
(a)

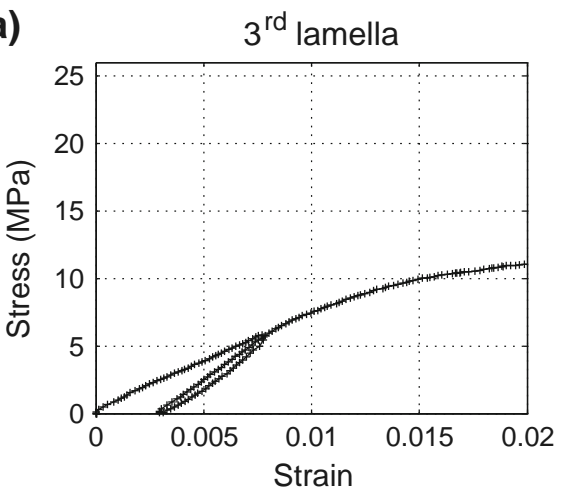

(c)

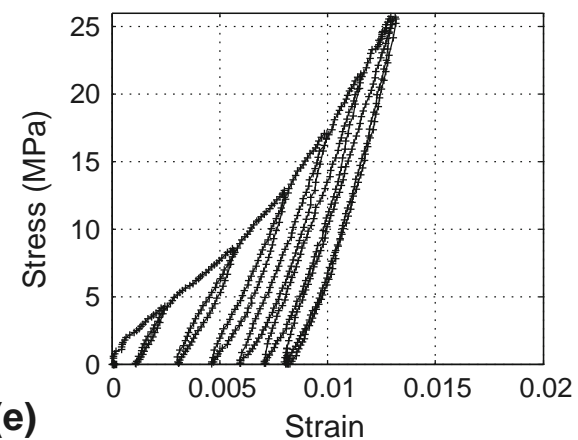

(b) $8^{\text {th }}$ lamella

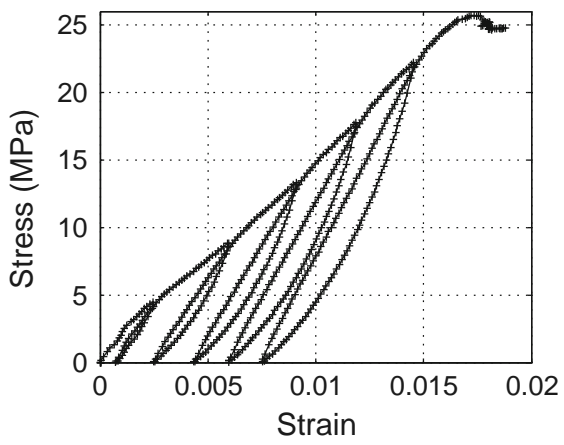

(d)

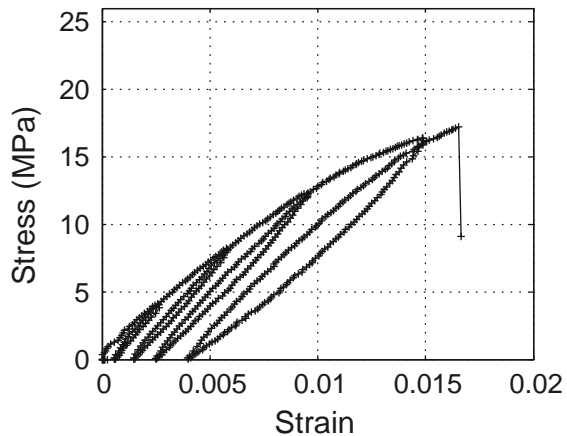

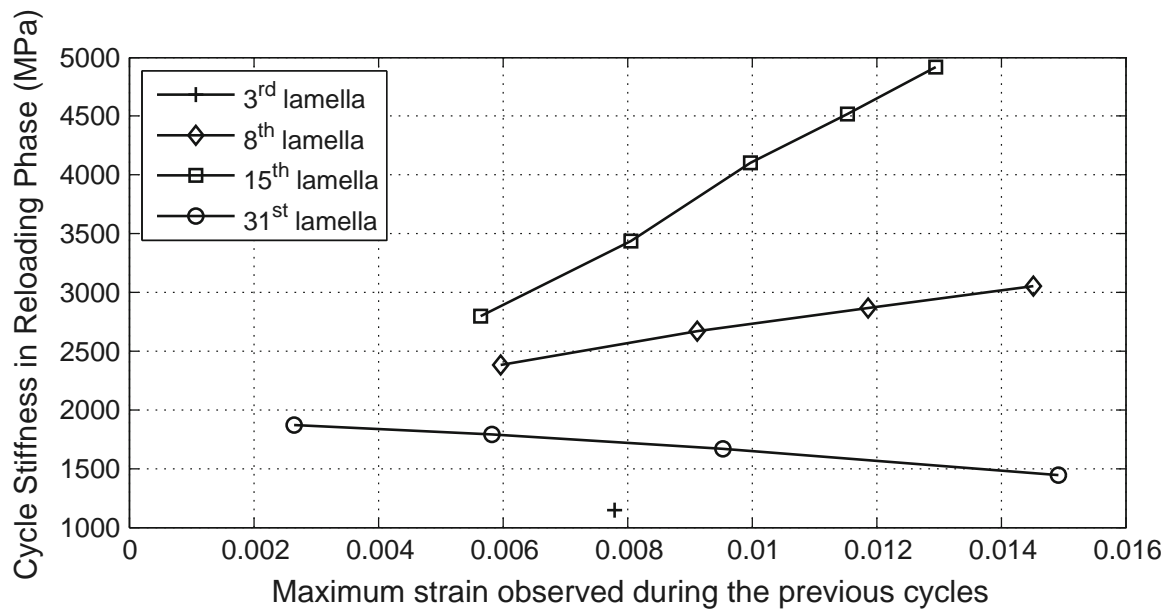

Fig. 6 Chosen TW stress/strain curves of the free tree felled on 20 July 2010. a third lamella cut at a distance of $0.4 \mathrm{~mm}$ from the first lamella; b eighth lamella cut at a distance of $1.4 \mathrm{~mm}$ from the first lamella; $\mathbf{c}$ fifteenth lamella cut at a distance of $2.8 \mathrm{~mm}$ from the first lamella; $\mathbf{d}$ thirty-first lamella cut at a distance of $6 \mathrm{~mm}$ from the first lamella; it is located in the previous annual ring (i.e. composed of $\mathrm{NW}$ ); e Cycle stiffness in the reloading phase, plotted according to the maximum strain observed during the previous cycles, obtained thanks to each previous curve (a)-(d) 
In order to characterize stress/strain curves easily, the CSRP was plotted according to the maximum strain applied during the previous cycle for each lamella. A typical curve is presented in Fig. 6e. It shows a linear relationship between CSRP and maximum applied strain. The entirety of the tested sample presented such linear behaviour. Hence, it is possible to characterize each sample by the two parameters of the linear curve: the slope and the $y$-intercept. These parameters are called gradS for the slope of the linear curve and S0 for the $y$-intercept. gradS represents the stiffness gradient of the wood according to the applied deformation, whereas S0 corresponds to the initial stiffness before loading. These parameters enable to visualize variation in TW mechanical behaviour along the radial position of the lamellas, regardless of the strain applied.

Figure 7 presents independently gradS and infradensity variations as a function of the radial distance from the first lamella for TW and OW samples, for a free tree and a staked-tilted tree felled at the end of the growing season. No clear pattern was observed with S0 (not shown). On the contrary, gradS variations along the radius of the tree were significant. First, gradS was positive for TW until a given depth into the radius of the tree, which corresponded to the decrease in infradensity (i.e. the growth ring limit). Then, in the growth ring limit region, there was a discontinuity in the TW curves, and gradS suddenly decreased to negative values. This shows that TW of the last growth ring exhibited strain hardening behaviour, whereas the wood of the previous growth ring (which is assumed to contain only NW) showed strain softening behaviour. For TW of staked-tilted tree, gradS tended to increase when it came closer to the growth ring limit discontinuity, whereas its infradensity tended to
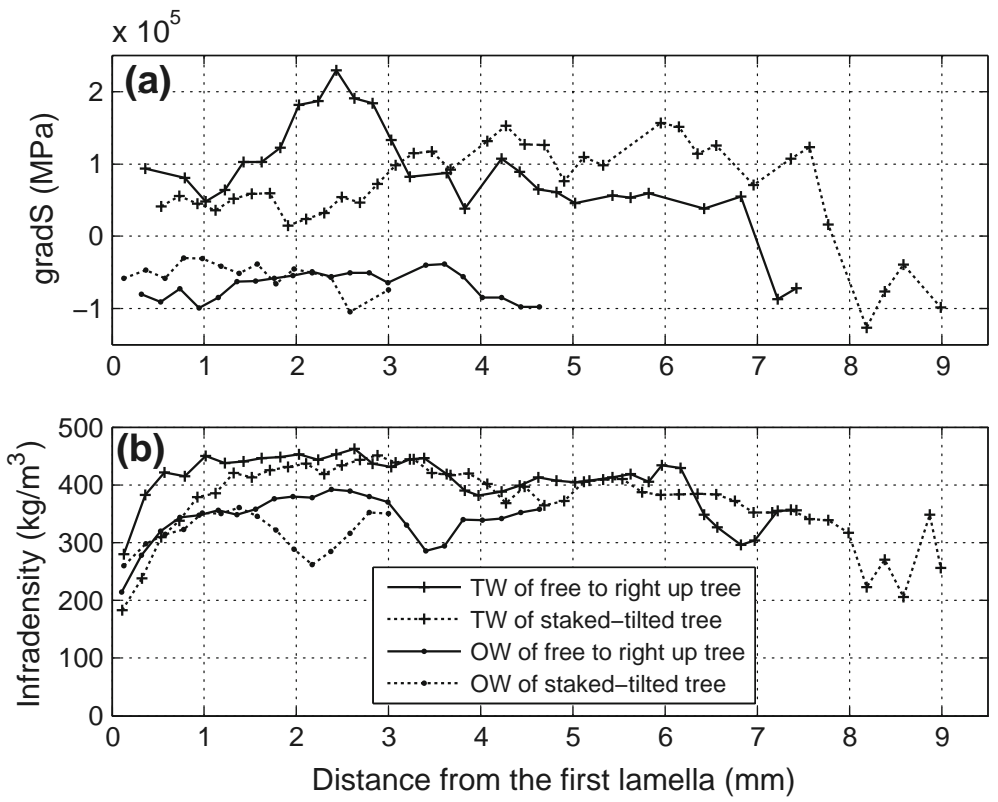

Fig. 7 Typical TW radial variation of a gradS and $\mathbf{b}$ infradensity of tension wood and opposite wood of a free tree and a staked-tilted tree felled on 3 August 2010 


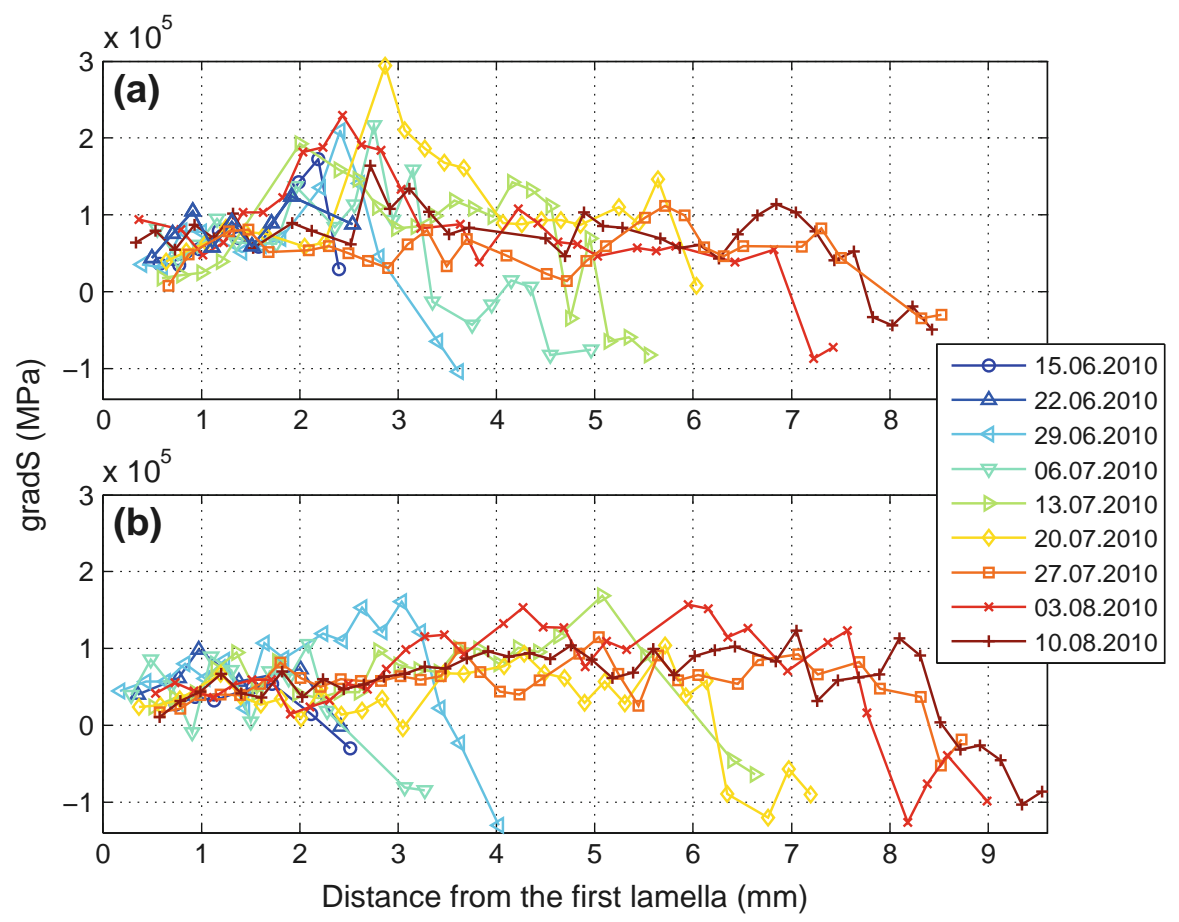

Fig. 8 TW radial variation in gradS according to the distance from the first lamella for a free trees and b staked-tilted trees felled at different dates throughout the growing season

decrease. The TW of a free tree in Fig. 7 presented very different behaviour, since there was a peak in gradS located at a distance of $2.4 \mathrm{~mm}$ from the first lamella. After this peak, gradS decreased to reach a more or less constant value, which was similar to the initial value observed before the peak. It then decreased suddenly to a negative value in the growth ring limit region, like the TW of the staked-tilted tree. While the TW gradS of the free tree exhibited such high variations, its infradensity remained constant. From a global point of view, there was no significant statistical relationship between gradS and infradensity for TW.

Considering OW in Fig. 7, gradS was negative for the free tree as well as for the staked-tilted tree, and gradS variations were very low compared to those of TW. Hence, OW exhibited strain softening behaviour that remained unchanged along the radius of the tree. Moreover, gradS values were similar to those of the NW of the previous annual ring, which is consistent with the similarity of the shapes of the stress/strain curves. As was the case for TW, there was no statistical relationship between gradS and infradensity for OW.

These comments are applicable to all the trees tested. Figure 8 presents the radial variation in gradS according to the distance from the first lamella. Figure 8a shows that the TW of all the free trees exhibited a gradS peak in the same region, 2-3 $\mathrm{mm}$ from the cambium (except one tree felled on 27 July 2010 for which gradS is constant). No peak was observed for staked-tilted trees (Fig. 8b). 


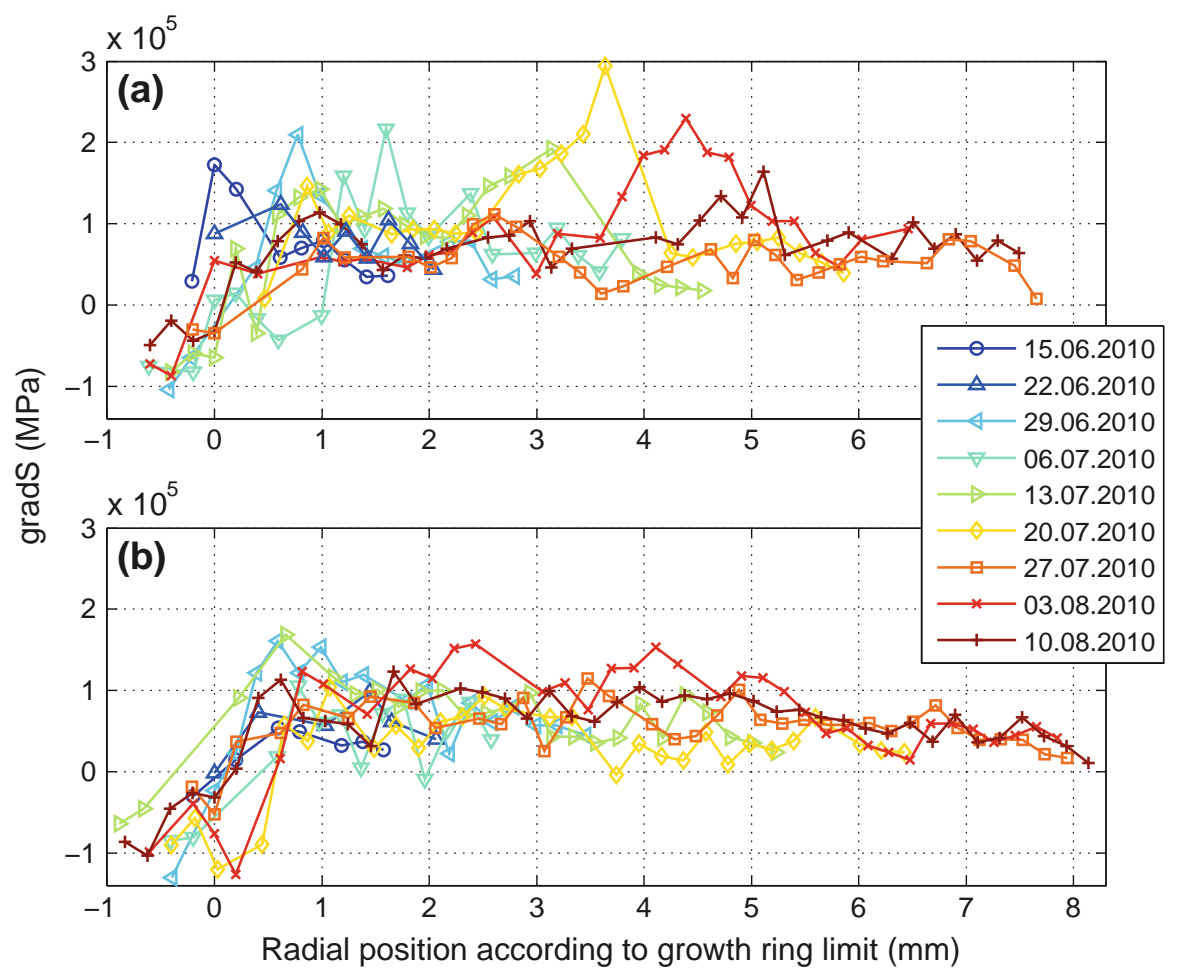

Fig. 9 TW radial variation in gradS according to the distance from the defined growth ring limit for $\mathbf{a}$ free trees and $\mathbf{b}$ staked-tilted trees felled at different dates throughout the growing season

Figure 9 presents the same data as Fig. 8, but here the $x$-axis represents the distance from the growth ring limit. Figure 9a shows that the gradS peak moved along the $x$-axis, since it was always at the same distance from the cambium. The peak amplitude seemed to change along the season, increasing until 20 July, then decreasing.

\section{Temporal variations in TW properties}

Representations depending on the growth ring limit (i.e. the radial position in the tree), such as infradensity in Fig. 5 and gradS in Fig. 9, can lead to a temporal representation of cell growth; assuming that all the trees grew at the same rate, data obtained from similar trees that were felled at different dates along the growing season can be considered as being primordial since the evolution of a single tree along the growing season. There was only one tree per series, which did not follow the hypothesis of equal growing rate and had a smaller amount of wood than trees that were felled earlier (the free tree felled on 3 August 2010, see Fig. 5a, and the staked-tilted tree felled on 6 July 2010, see Fig. 5b). Thus, infradensity and gradS variations are sufficiently clear to characterize the temporal evolution of TW. 

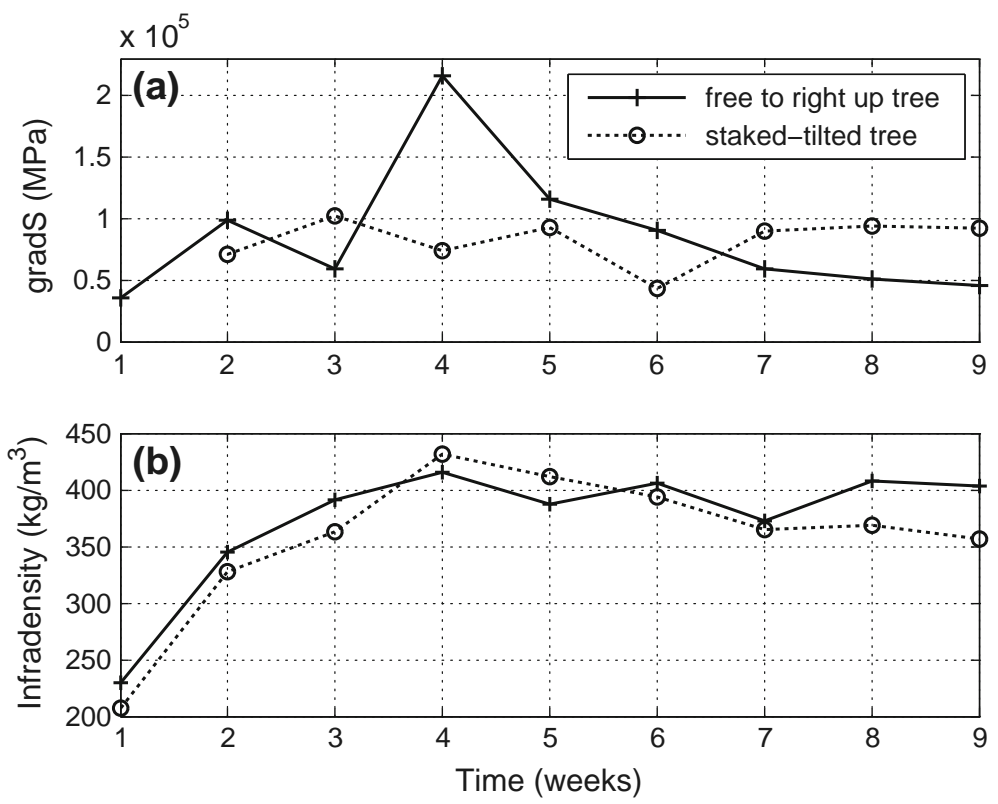

Fig. 10 Temporal variation in a gradS and $\mathbf{b}$ infradensity for a TW cell located at a distance of $1.6 \mathrm{~mm}$ from the growth ring limit. Data were obtained thanks different trees felled at different times throughout the growing season in 2 series of experiments: free trees and staked-tilted trees

In this manner, Fig. 10 enables a comparison of the temporal behaviour of cells from a free tree and a staked-tilted tree located at a given radial position relative to the growth ring limit $(1.6 \mathrm{~mm})$. In this figure, the radial position was chosen in a zone where gradS reached a maximum. However, the following observations would be similar if a different radial position had been chosen. Figure 10a presents the temporal variation of gradS, while Fig. 10b presents the temporal variation of the corresponding infradensity. Figure $10 \mathrm{~b}$ shows that for a free tree as for a stakedtilted tree, infradensity increased until a steady state was reached about 2 weeks after cell creation by the cambium. While infradensity increased, gradS was low and steady (Fig. 10a). Once infradensity stopped increasing, there was a high increase in gradS for the free tree, which was not observed for the staked-tilted tree. Subsequently, the gradS of free tree decreased and reached a value similar to the initial one, while the gradS of the staked-tilted tree remained constant. Hence, the temporal variation in the mechanical behaviour of the cells was significantly different between the trees that were free to right up and those that were staked.

\section{Discussion}

The comparison between TW and OW highlights the profound difference in mechanical behaviour between these two materials extracted from the same living tree. Gilani and Navi (2007) have put forward an isotropic damage model of a cell under tension, which could explain this difference by a complex process mixing 
MFA changes and multiple damages to the lignin and hemicelluloses matrix. In this model, MFA reduction increases stiffness, whereas damage to the matrix leads to the opposite effect. Hence, in the present work, TW behaviour could be explained by the reduction in MFA, which would be preponderant compared to damage. Otherwise, for OW samples, damage would overcome the effect of MFA reduction and, as a consequence, stiffness would decrease as applied strain increases. To the authors' knowledge, such behaviour has never been described in literature for wood samples of greater dimensions, and Navi et al. (1995) reported that such behaviour is not observed in bulk wood. Hence, there are size effects that are not explained by the Gilani and Navi model. This model refers to the behaviour of a single fibre considered as a hollow cylinder, whereas the samples tested in the present study contain several fibres. As MFA in the G layer is nearly zero, its reduction cannot explain the stress hardening behaviour. It is possible that stress hardening is due to changes of the MFA in S2 layer, but in this case, it implies some slippage between the G layer and the S2 layer, as suggested in Burgert (2006). In addition, at a mesoscopic scale, there could be deformations of the assembly of fibres which could be significant in the behaviour of the whole sample under longitudinal tension. In particular, another unpublished result performed in the authors ' group had shown that Poisson's ratio was lower for TW than for OW, which highlights the differences in the lateral shrinkage of their structure. Such effects could also explain the overestimation of the stiffness in the Gilani and Navi model. To go further in this investigation, tensile tests performed in situ using ESEM should be useful.

Despite the complex mechanical behaviour of green wood, this study highlights that the strain hardening behaviour of TW presents a linear relationship between CSRP and maximum applied strain. This linear relationship finds no clear explanation. However, since gradS does not depend on the strain applied, it allows the mechanical behaviour of a sample to be characterized irrespective of tensile test conditions (especially applied strain). Because the experimental protocol used is strictly the same for the entirety of the tested samples, changes in gradS can only be explained by changes in the composition or the structure of the wood. As a consequence, gradS is an appropriate indicator of the mechanical behaviour of lamellas cut at different stages of maturation.

Infradensity is usually employed as an indicator of wood stiffness. In the present study, infradensity ranged from a very low value in the first lamella (i.e. cambium or close to it) to a maximum at a distance of less than $1.5 \mathrm{~mm}$ from the first lamella, in less than 2 weeks. Hence, the maturation zone should be limited to this region. However, considering the gradS of TW from free trees (Fig. 8a), a significant increase appears at a distance of $2-3 \mathrm{~mm}$ from the first lamella, in a zone where there is no significant variation in infradensity. As no infradensity variation must signify no material addition, gradS variation must be caused by micro-structural changes in cells. Moreover, no statistically significant relationship was found between gradS and infradensity for either TW or OW. As a result, infradensity is not a sufficient parameter to evaluate the mechanical behaviour of green wood.

The gradS peak, located at the same distance from the cambium for all the free trees (Fig. 8), indicates unusual behaviour in the maturation process. Assuming that all the tested trees were identical and that they grew at the same rate, the temporal 
evolution of the maturation of the cells was plotted (Fig. 10). This highlights the fact that important changes in the mechanical behaviour of lamellas of free trees appear after cell wall thickening. As previously mentioned, the micro-structure of the wood was suspected to be responsible for changes in gradS, but the reasons for these changes, especially the high variation 2-4 weeks after cell creation, remain enigmatic. Moreover, no temporal variation in gradS appeared clearly for stakedtilted trees, while they underwent gravitropic stress and produced TW. Thus, the gradS peak observed for free trees may be related to the righting-up process itself.

Infradensity and gradS variations are large in a zone situated several millimetres away from the cambium, which lead to large temporal variations in these parameters up to a growth time of the cells of 4 weeks. Hence, it was concluded that maturation is not an instantaneous phenomenon and that cells undergo a temporal evolution in their properties. As a consequence, mechanical pre-stresses in trees must also not appear immediately. To the authors' knowledge, such temporal evolutions are not taken into account in biomechanical models of tree re-orientation. Their importance may not be negligible, as suggested by Coutand et al. (2007); the accuracy of these models could be improved thanks to the results of the present study.

\section{Conclusion}

In this study, longitudinal mechanical tensile tests and infradensity measurements were performed on a large quantity of thin green wood samples, which were representative of the last growth ring of tilted poplar trees. There were two series of experiments with nine trees that were free to right up and nine trees that were staked in a tilted position. The objective was to characterize spatially and temporally the variations in TW intra-ring mechanical behaviour during radial growth and gravitropic response.

Tensile tests highlighted the particularly complex mechanical behaviour of green wood thin slices, such as permanent sets in terms of displacement and straindependent stiffness. TW samples presented strain hardening behaviour, whereas $\mathrm{OW}$ of the last growth ring and NW of the previous growth ring presented strain softening behaviour. In spite of this, the experimental protocol used allowed to define a mechanical quantity (gradS) that characterizes the radial evolution of the mechanical behaviour of TW lamellas in the last growth ring.

Infradensity measurements performed on the tested samples did not show a statistical relationship with gradS, which lead to the conclusion that infradensity (i.e. the quantity of wood) is not sufficient to evaluate the mechanical behaviour of green wood thin slices. Moreover, this study shows that maturation is not an instantaneous phenomenon, but that cells undergo temporal variations in their properties. For the poplar used in this work, infradensity first increased in the first millimetres after the cambium, which shows that cell wall thickness increased for about 2 weeks, then a gradS peak occurred and then, 4 weeks after cell creation, gradS returns to its initial value. Such variations in gradS were not observed for staked-tilted trees, highlighting the fact that this behaviour must be part of the maturation in the righting-up process of the tree. 
Acknowledgments The authors would like to thank Dr. M. Eder and Dr. I. Burgert of the Max Planck Institute of Colloids and Interfaces (Potsdam, Germany) for the ESEM observations.

\section{References}

Alméras T, Fournier M (2009) Biomechanical design and long-term stability of trees: morphological and wood traits involved in the balance between weight increase and the gravitropic reaction. J Theor Biol 256:370-381

Baley C (2002) Analysis of the flax fibres tensile behaviour and analysis of the tensile stiffness increase. Compos Part A: Appl Sci Manuf 33:939-948

Bjurhager I, Berglund LA, Bardage S, Sundberg B (2008) Mechanical characterization of juvenile European aspen (Populus tremula) and hybrid aspen (Populus tremula $\times$ Populus tremuloides) using full-field strain measurements. J Wood Sci 54:349-355

Burgert I (2006) Exploring the micromechanical design of plant cell walls. Am J Bot 93:1391-1401

Clair B, Alméras T, Pilate G, Jullien D, Sugiyama J, Riekel C (2010) Maturation stress generation in poplar tension wood studied by synchrotron radiation microdiffraction. Plant Physiol 152:1650-1658

Coutand C, Fournier M, Moulia B (2007) The gravitropic response of poplar trunks: key roles of prestressed wood regulation and the relative kinetics of cambial growth versus wood maturation. Plant Physiol 144:1166-1180

Coutand C, Mathias JD, Jeronimidis G, Destrebecq JF (2011) TWIG: a model to simulate the gravitropic response of a tree axis in the frame of elasticity and viscoelasticity, at intra-annual time scale. J Theor Biol 273:115-129

Déjardin A, Laurans F, Arnaud D, Breton C, Pilate G, Leplé JC (2010) Wood formation in angiosperms. CR Biol 333:325-334

Fournier M, Baillères H, Chanson B (1994) Tree biomechanics: growth, cumulative pre-stresses and reorientations. Biomimetics 2:229-251

Fournier M, Stokes A, Coutand C, Fourcaud T, Moulia B (2006) Tree biomechanics and growth strategies in the context of forest functional ecology. In: Speck T, Rowe N, Herrel A (eds) Ecology and biomechanics: a mechanical approach to the ecology of animals and plants. CRC Press, Boca Raton, pp 1-34

Gilani M, Navi P (2007) Experimental observations and micromechanical modeling of successivedamaging phenomenon in wood cells' tensile behaviour. Wood Sci Technol 41:69-85

Goswami L, Dunlop JWC, Jungnikl K, Eder M, Gierlinger N, Coutand C, Jeronimidis G, Fratzl P, Burgert I (2008) Stress generation in the tension wood of poplar is based on the lateral swelling power of the G-layer. Plant J 56:531-538

Hild F (2002) CorreliLMT: a software for displacement field measurements by digital image correlation. Internal Technical Report 254, LMT

Jourez B, Avella-Shaw T (2003) Effect of gravitational stimulus duration on tension wood formation in young stems of poplar (P. euramericana cv 'Ghoy'). Ann For Sci 60:31-41

Jourez B, Riboux A, Leclercq A (2001) Anatomical characteristics of tension wood and opposite wood in young inclined stems of poplar (Populus euramericana cv "Ghoy"). Iawa J 22:133-157

Jourez B, Vainopoulos C, Hébert J (2003) Effect of intensity of gravitational stimulus artificially induced on growth and tension wood formation in young shoots of poplar (P. euramericana cv 'Ghoy'). Ann For Sci 60:789-802

Moliński W, Krauss A (2008) Radial gradient of modulus of elasticity of wood and tracheid cell walls in dominant pine trees (Pinus sylvestris L.). Folia For Pol 39:19-29

Navi P, Rastogi PK, Gresse V, Tolou A (1995) Micromechanics of wood subjected to axial tension. Wood Sci Technol 29:411-429

Plomion C, Leprovost G, Stokes A (2001) Wood formation in trees. Plant Physiol 127:1513-1523

Scurfield G (1973) Reaction wood: its structure, function. Science 179:647-655

Sinnott EW (1952) Reaction wood and the regulation of tree form. Am J Bot 39:69-78

Yamamoto H, Masato Y, Takashi O (2002) Growth stress controls negative gravitropism in woody plant stems. Planta 216:280-292 